JELTL (Journal of English Language Teaching and Linguistics) e-ISSN: 2502-6062, p-ISSN: 2503-1848

2019, Vol. 4(1)

www.jeltl.org

\title{
A Discourse Analysis: Cohesion of the Introduction Section of Research Article
}

\author{
Anis Firdatul Rochma \\ Yogyakarta State University \\ afrochma@gmail.com \\ Sulis Triyono \\ Yogyakarta State University \\ sulis@uny.ac.id
}

\begin{abstract}
As an effort to give a contribution to the existing knowledge, it is expected for the undergraduate students to compose an engaging research article in order to convince the readers about the importance of the research article. However, there is only a little attention given to the articles written by the undergraduate students although it is considered very critical to examine whether the exposure of English academic writing has significantly enhanced the writing competence of the students. Furthermore, as it is also very crucial to build a meaningful semantic meaning among the sentences in order to disclose the worthiness of the research article, it is essential to analyze the cohesion of the research article written by the undergraduate students. Henceforth, the present research is projected to investigate the cohesion of the research articles written by the undergraduate students of English Language Teaching. As the introduction section of a research article is likely to be an area to portray the logical explanation of the research, the present research solely focuses on examining the cohesion of the introduction section of a research article. By adopting a qualitative design and involving several steps to analyze the introduction section, it is revealed that the grammatical cohesion is considered to be the most utilized type of cohesion in writing the introduction section. Still, the lexical cohesion is also necessary to build an eloquent semantic meaning about the topic as well as the importance of the research article.
\end{abstract}

Keywords: Discourse analysis, cohesion, an introduction section, research article

JELTL (Journal of English Language Teaching and Linguistics), 4(1), 2019 
Anis Firdatul Rochma \& Sulis Triyono

\section{INTRODUCTION}

At the present moment, composing a research article is believed to be a high requirement to be fulfilled by not only the scientist but also the university students as it is expected for them to give contributions to the existing knowledge of a particular subject by carrying out and composing a research article. Generally, a research article is written in four sections, including the introduction section, the methods section, the results section, as well as the discussion section.

In most cases, an introduction section is believed to be the first area of a research article to be read (Safnil, 2013). Thus, it is very crucial to compose a fascinating and convincing introduction section of a research article in order to engage the attention of readers. Employing an appropriate rhetorical convention, in which there are several macro and microstructures to be adopted, is considered to be one of several advantageous strategies in composing an engaging introduction section of research articles. In fact, numerous researchers had been executed by several researchers, such as Mirahayuni (2001), Hirano (2009), Loi \& Evans (2010), Sheldon (2011), and Rakhmawati (2013), in which each research aimed in examining the rhetorical conventions employed in writing the introduction section of research article by adopting the Create a Research Space (CARS) model by Swales (2004), a widely international well-known rhetorical convention, as the primary framework.

Nevertheless, there is too much broad attention that has been given to the research articles which are written by the experts of a particular subject and published in several reputable journals. In other words, there is only a little attention that has been paid to the research articles written by the undergraduate students although it is also likely for the undergraduate students to add some contributions for the development of current knowledge by composing a research article. Above all, there is an unclear fact whether the exposure of English writing practice within the academic writing class successfully develops and enhances the writing competence of the undergraduate students, including the competence in writing the introduction section of research article cohesively.

In writing an introduction section of research article cohesively, it is expected for the undergraduate students to be able to associate one sentence to its predecessors and successors in order to compose a well-connected text. As it is very essential to write an introduction section which is in accordance to not only the rhetorical convention but also the theory of cohesion, it is believed to be crucial to examine the introduction section of research article written by the undergraduate students. Henceforth, the present research is merely projected to evaluate the cohesion of the introduction section within the research article written by undergraduate students as one of the strategies in justifying the research importance.

\section{LITERATURE REVIEW}

The present section discloses some important points with due regard to the discourse analysis, especially the concept of cohesion to be employed in writing the introduction section of a research article. 


\subsection{The Introduction Section of Research Article}

Generally, a research article is composed of four sections, which are the introduction section, method section, result section, and discussion section as well. Each section of a research article plays an important role in presenting a current knowledge pertaining to a particular subject as well as in portraying the reliability of the current knowledge. That is to say, the introduction section is a subdivision in which the writer is expected to precisely aim the research points through plainly highlighting the subject of the research that is going to be executed (Jordan, 1999). In addition, as the fundamental purpose of the introduction section of a research article is to capture the readers' attention by composing the research article as fascinatingly as possible, it is considered vital to intelligibly present a short history of the research subject, the primary research findings and theories, as well as the current situation pertaining to the research subject (Holtom, 1999).

Additionally, it is critical for the introduction section of a research article to explore any fundamental theories pertinent to the research subject by outlining the current status of the theories or by portraying a brief history of the research subject (Turabian, 2013). Moreover, the introduction section is also expected to associate the relevant findings and theories and identify any matters related to the prior research methods to announce the current research method that has been modified and developed (Sternberg \& Sternberg, 2010). Above all, it is also necessary for the introduction section of a research article to apparently and briefly assert an explanation of the preceding research in order to put the current research where it corresponds to the preceding research (Kendal, 2015).

Primarily, the introduction section of a research article is composed to fulfill two fundamental functions, which are to show the logical descriptions of the research article as well as to convince the readers to read the overall text of research article (Swales, Feak, Johns, \& Arbor, 2004). That is to say, as it is very urgent to introduce and correlate the current research article with the preceding knowledge within a specific subject, an appropriate writing strategy needs to be selected and carried out in composing a stimulating introduction section of a research article. One of several strategies to compose a captivating introduction section is by adopting the concept of cohesion into the process of writing a research article. By adopting the concept of cohesion, especially by involving the grammatical and lexical, it is likely for the introduction section to make an impression on the readers with a fascinating introduction section of a research article.

Several piece of research pertinent to the introduction section of a research article had been executed by some researchers. One of those researches was conducted by Hirano (2009) in which the research was projected to examine 20 research articles of Applied Linguistics. In addition, Loi \& Evans (2010) also carried out a research related to the introduction section of a research article in which the writing structure of 40 research articles of educational psychology was analyzed. Another research about the introduction section of a research article was also executed by Sheldon (2011) in which 54 research articles of Applied Linguistics were analyzed. However, the aforementioned researches solely focused on the micro and macro strategies of the introduction section of a research article in which the Create a Research Space (CARS) model 
by Swales (2004) was adopted as the main framework. As it is very crucial to compose an introduction section of a research article in which each sentence is associated to each other, it is considered important to carry out a research to investigate and examine the cohesion of the introduction section of a research article.

\subsection{Cohesion}

As a means of communication, language is regarded as a crucial device employed to create an interconnection between the author and the writer by displaying the writer's use of language to portray approval and disapproval, certainty and uncertainty, as well as acceptance and rejection (Briones, 2016). That is to say, any language conventions employed by the author is considered able to uncover the content of the written work as well as discover the impact of the written works on the readers. One of any language conventions that can be employed to display the author's perspective on any particular issues is by involving the concept of cohesion within the writing process. As by enhancing a considerable sense of writing, a writer is supposed to be able to enhance the accuracy of productive vocabularies as well in order to solely focus on the structure and vocabulary of the information (Johnson, 2017).

The term cohesion was introduced by Halliday (1976) in which it is believed to be an indicator in deciding whether a text is only a group of unrelated sentences or a well-connected sentence. Another definition of cohesion is related to particular words as well as grammatical features in which it relates one sentence to its predecessors and successors within a text (Hoey, 1996). In other words, cohesion offers a surface structure linkage among elements of a text (Tarnyikova, 2009). As it is considered very crucial to write a particular sentence or a particular text as cohesively as possible, several piece of research has been carried out by numerous researchers, such as Abimanyu (2016), Andayani, Seken, \& Marjohan (2014), and Manan \& Raslee (2018) in order to reveal the cohesion of each text being examined in accordance with the cohesion classification proposed by Halliday (1976).

The classification of cohesion was proposed by which was divided into 2 categorizations (M. A. K. Halliday, 1976), namely grammatical cohesion and lexical cohesion. The grammatical cohesion, in which it is related to the text structure of grammar within a text, consists of reference, substitution, ellipsis, and conjunction. Meanwhile, the lexical cohesion which is related to the words within a text consists of repetition and collocation.

\subsubsection{Reference}

The first category of grammatical cohesion, which is the reference, possesses a property of specificity or definiteness. In other words, reference provides a certain type of cohesion that is related to a specific and definite meaning of information which is referred to within a sentence or a text (M. A. K. Halliday, 1976). Even though the items of the reference are not inevitably encoded in the text, however, it should relate and match to the semantic properties which are referred to. Furthermore, the reference offers three continual analyses including naming, situational reference, as well as textual reference. Naming is a continual analysis of reference 
which refers to an independent thing as described and identified in a situation of a context. On the other hand, the situational reference provides a continual analysis of reference in which it refers to a thing as described within the context of a situation. Moreover, the third continual analysis of reference which is the textual reference refers to a thing as described within the surrounding text.

Besides the continual analyses, the reference has also been divided into three forms, namely personal reference, demonstrative reference, and comparative reference. The personal reference indicates the person involved in a text by specifying the roles of each person. The term person within the personal reference involves personal meaning (individual), impersonal meaning (groups of individuals), and non-personal (objects). In other words, the personal reference may include personal pronouns, possessive determiners, as well as possessive pronouns. The second form of reference, which is the demonstrative reference, refers to a form of reference which is described by the scale of proximity that has a function either as the head or the modifier, or as the adjunct, by employing "'this" or "that" as a reference to singular noun and "these" or "those" as a reference to plural noun. The comparative reference, which is the third form of reference, tends to identify the similarity among several things within a text. The adjectives of comparison, including deictic and epithet, as well as the adverbs of comparison, including adjunct, can be functioned to be a framework in expressing the comparison.

\subsubsection{Substitution}

The second category of grammatical cohesion, which is the substitution, refers to a replacement of an item with another item that has the same grammatical classification. Due to the fact that it can be functioned as a noun, a verb, or even a clause, the substitution is divided into three forms, namely nominal substitution, verbal substitution, as well as clausal substitution (M. A. K. Halliday, 1976).

The first forms of substitution, which is the nominal substitution, refers to the head of a nominal group which holds a status as the final position within the group. In other words, the substituted item should hold the same function and position as the previous item even though the numbers of the items are not necessarily to be exactly the same. Furthermore, the possible component of items in the nominal substitution should be in a form of countable nouns. The verbal substitution, as the second form of substitution, can be functioned as the head of a verbal group that also holds a status as the final position within the group. The items or elements in a text that represents an event or an action can be substituted by ' $d o$ '. In addition, in substituting the items within a text, the ' $d o$ ' can be expressed with the following morphological scatter, such as doing, did, and done. The third form of substitution, which is the clausal substitution, refers to a process of substituting the whole clause instead of elements within a text. Even though the clausal substitution is able to take control over three environments, namely report, condition, and modality, it has a limitation in which it can only substitute the declarative sentence.

JELTL (Journal of English Language Teaching and Linguistics), 4(1), 2019 
Anis Firdatul Rochma \& Sulis Triyono

\subsubsection{Ellipsis}

Ellipsis is the third category of grammatical cohesion which refers to a structural relation established within a text. Ellipsis is able to explain the structure in a sentence as well as show a correlation between the sentences and the important aspect of a texture. Even though ellipsis does not necessarily discover the structural correlation between the sentences, still, the ellipsis is considered as a vital aspect to examine the grammatical cohesion and the written discourse analysis as well. The nominal ellipsis, verbal ellipsis, as well as clausal ellipsis are the three forms of ellipsis provided within the grammatical cohesion (M. A. K. Halliday, 1976).

The first form of ellipsis, which is the nominal ellipsis, refers to a type of ellipsis in which it deals with the nominal group by using premodifiers, such as numerative, deictic, epithet, and classifier to modify the head within a text. The verbal ellipsis, as the second type of ellipsis, refers to a process of interpretation within a verbal group system by not fully expressing the presupposed next verbal group with the systemic features. Meanwhile, the third type of ellipsis, which is the clausal ellipsis, refers to a type of ellipsis that occurs in clausal extent. The clausal ellipsis involves a process of omission in both modal and prepositional elements, in which the modal elements consist of the subject and the finite element in the verbal group while the prepositional elements consist of the remainder of the verbal group as well as any other complements occurred.

\subsubsection{Conjunction}

The elements of conjunctive are solely focuses on creating cohesion through virtues of their specific meaning. Generally, the conjunctive elements consist of specific meanings in which it correlates with the following text. In addition, the conjunctive element has a function in relating the linguistic elements occurred in sequence. The classification of conjunctive elements is divided into four forms, namely additive, adversative, causal, and temporal (M. A. K. Halliday, 1976).

The first form of conjunction, which is the additive conjunction, connects additional information to the existing ones which have equal positions in the structure of the sentences. In other words, the additive conjunction refers to a type of cohesion which is based on the coordination of the text. The adversative conjunction, as the second type of the conjunctive elements, focuses on the expressions of contrary expectation. Furthermore, the third type of conjunctive elements, which is the causal conjunctive, defines a relationship between the cause and the consequence (Nunan, 1993). In order to form a cohesive chain, the results, reasons, and purposes are included in the causal relation. Moreover, the temporal conjunction, which is the fourth as well as the last form of conjunctive elements, occurs within a text in which the events are related in terms of timing of their occurrence (Nunan, 1993). The temporal relation is usually expressed by using various expressions, such as then, and then, afterward, after that, and a wide range of other expressions. 


\subsection{Lexical Cohesion}

The lexical cohesion deals with the cohesive effect within the selections of vocabulary or non-grammatical elements. The lexical cohesion usually appears in discourse through reproducibility, or so-called reiteration, and co-occurrence, or so-called collocation (M. A. K. Halliday, 1976).

\subsubsection{Reiteration}

The term of reiteration is related to the repetition of a lexical item in which it is either repeated directly or through the implementation of a synonym and a superordinate, or a generally related word (M. A. K. Halliday, 1976). A synonym pertains to the number of words which have similar meanings to the previous word being referred. Furthermore, the superordinate word refers to a word which has more general classification and categorization compared to the word being mentioned previously. Meanwhile, the general word is related to the most general category of the word which is being referred.

\subsubsection{Collocation}

Collocation pertains to the tendency or words which have a similar context which due regard to the creation of a cohesive force in adjacent sentences occurred. Several language researchers consider collocation as the potential element causing an arising issue within the written discourse analysis since it is quite tricky to decide whether the cohesive relationship exists or not (Nunan, 1993). Collocation pertains to the tendency or words which have a similar context which due regard to the creation of a cohesive force in adjacent sentences occurred. Several language researchers consider collocation as the potential element causing an arising issue within the written discourse analysis since it is quite tricky to decide whether the cohesive relationship exists or not (Nunan, 1993).

\section{RESEARCH METHODS}

The present research is carried out qualitatively in which a content analysis is adopted to examine the introduction section of research article written by the undergraduate students of English Language Teaching. The analysis evaluates the cohesion of the introduction section by adopting the concept of cohesion, including the grammatical and lexical cohesion, proposed by Halliday (1976). In addition, numerous steps are also included to examine ten research articles written by the undergraduate students of English Language Teaching, especially to investigate the cohesion of the introduction section of a research article written by the undergraduate students, involving reading the titles, abstract, and key points; identifying the frequent appearances of the grammatical and lexical cohesion; as well as identifying the linguistics features and discourse clues to grasp the importance of the research articles in contributing a new development to the prior knowledge.

\section{FINDINGS}

The findings pertaining to the various types of cohesion employed in the introduction section of a research article are elaborated within the present section. 
Table: 1 The Occurrence of the Cohesion Types

\begin{tabular}{|c|c|c|c|c|}
\hline \multicolumn{3}{|c|}{ Types of Cohesion } & $\begin{array}{c}\text { Frequent } \\
\text { Appearances }\end{array}$ & Percentage \\
\hline \multirow{13}{*}{$\begin{array}{c}\text { Grammatical } \\
\text { Cohesion }\end{array}$} & \multirow{3}{*}{ References } & Personal Reference & 10 & $100 \%$ \\
\hline & & $\begin{array}{c}\text { Demonstrative } \\
\text { Reference }\end{array}$ & 6 & $60 \%$ \\
\hline & & $\begin{array}{l}\text { Comparative } \\
\text { Reference }\end{array}$ & 6 & $60 \%$ \\
\hline & \multirow{3}{*}{ Substitution } & $\begin{array}{c}\text { Nominal } \\
\text { Substitution }\end{array}$ & 0 & $0 \%$ \\
\hline & & Verbal Substitution & 0 & $0 \%$ \\
\hline & & $\begin{array}{c}\text { Clausal } \\
\text { Substitution }\end{array}$ & 0 & $0 \%$ \\
\hline & \multirow{3}{*}{ Ellipsis } & Nominal Ellipsis & 7 & $70 \%$ \\
\hline & & Verbal Ellipsis & 3 & $30 \%$ \\
\hline & & Clausal Ellipsis & 7 & $70 \%$ \\
\hline & \multirow{4}{*}{ Conjunction } & $\begin{array}{c}\text { Additive } \\
\text { Conjunction } \\
\end{array}$ & 6 & $60 \%$ \\
\hline & & $\begin{array}{l}\text { Adversative } \\
\text { Conjunction }\end{array}$ & 6 & $60 \%$ \\
\hline & & Causal Conjunction & 8 & $80 \%$ \\
\hline & & $\begin{array}{c}\text { Temporal } \\
\text { Conjunction } \\
\end{array}$ & 6 & $60 \%$ \\
\hline \multirow{2}{*}{$\begin{array}{c}\text { Lexical } \\
\text { Cohesion }\end{array}$} & \multirow{2}{*}{\multicolumn{2}{|c|}{$\begin{array}{l}\text { Reiteration } \\
\text { Collocation }\end{array}$}} & 1 & $10 \%$ \\
\hline & & & 0 & $0 \%$ \\
\hline
\end{tabular}

Related to the grammatical cohesion, the data analysis presented in the table 1 indicates that personal reference was implemented within all of the research articles (100\%) outlining the fact that the undergraduate students were likely to specify the roles of each individual, groups of individual, as well as objects, to create a cohesion within the introduction section of a research article. In addition, $60 \%$ of 10 research articles analyzed employed the demonstrative reference to signify the singular as well as plural nouns established within the introduction section of a research article. Furthermore, $60 \%$ of 10 research articles written by the undergraduate students utilized the comparative reference as a strategy in identifying the similarity among the research objects to create a cohesion. Meanwhile, as a strategy to replace an element with another element that has the same grammatical classification, it was discovered that none of the substitution forms was employed in the introduction section of research article written by the undergraduate students.

Additionally, related to another type of grammatical cohesion, namely the ellipsis, it was discovered that $70 \%$ of 10 research articles employed the nominal ellipsis to signify the nominal group within the introduction section. Also, $30 \%$ of 10 research articles implemented the verbal 
ellipsis to deal with the process of interpretation in a verbal group system within the introduction section. Furthermore, $70 \%$ of 10 research articles included the clausal ellipsis within the introduction section as a strategy of omission in both modal and prepositional elements.

Above all, pertinent to the other type of grammatical coherence, namely the conjunction, it was uncovered that $60 \%$ of 10 research articles involved the additive conjunction as a strategy to associate the additional information in creating a cohesion within the introduction section of a research article. Similarly, $60 \%$ of 10 research articles analyzed was discovered to implement the adversative conjunction in focusing on the expression of contrary expectation. In addition, $80 \%$ of 10 research articles employed the causal conjunction to point out the interconnection of the causes and consequences. What is more, $60 \%$ of 10 research articles were recognized to implement the temporal conjunction to define the related events in terms of timing of the occurrences.

The other type of cohesion, namely the lexical cohesion, was also revealed to be employed within the introduction section of research article written by the undergraduate students majoring in English Language Teaching. However, there was only one type of lexical cohesion implemented, which was the reiteration. As a strategy to repeat a particular word with the synonym or superordinate words, only $10 \%$ of 10 research articles were discovered to implement reiteration in creating a cohesion within the introduction section. On the contrary, the collocation as the other type of lexical cohesion was nowhere to be found within the introduction section of research article written by the undergraduate students of English Language Teaching.

\section{DISCUSSION}

The comprehensive discussions pertinent to the various types of cohesion employed in the introduction section of research article written by the undergraduate students majoring in English Language Teaching are elaborated within the present section.

\subsection{Grammatical Cohesion}

As one of the two types of cohesion, the grammatical cohesion is generally implemented to display a semantic relationship among the sentences by employing the grammatical elements. In the present research, it was discovered that reference was the most frequently utilized type of grammatical cohesion. In contrast, none of the introduction section of research articles written by the undergraduate students of English Language Teaching employed substitution as a means to present a grammatical cohesion. The results of the present research are similar to the previous research conducted by Abimanyu (2016) in which reference appears with the highest number within numerous texts being examined with the total number of 663 occurrences. In addition, another prior research also reveals that reference is the highest type of grammatical cohesion employed in comparison to the other types of grammatical cohesion with the total percentage of $70.77 \%$ (Andayani et al., 2014).

JELTL (Journal of English Language Teaching and Linguistics), 4(1), 2019 
Anis Firdatul Rochma \& Sulis Triyono

\subsubsection{Reference}

As the first type of reference, the personal reference is employed in all of the research articles selected to be analyzed, particularly in the introduction section of a research article. Several instances of the implementation of personal reference in the introduction section are displayed as follows.

(1) Harmer (2001:282) also says that a video is not only a great aid to see language in use such as comprehension since students are able to see general meaning and moods.... He also mentions that for all of the reasons mentioned, most students showed an increased level of interest when they had a chance to see language in use as well as hear it (Article 1).

(2) In fact, it was not easy for the students to write a paragraph even a sentence. They needed a long time to think about what they would write and how to write their ideas (Article 3).

(3) English teachers should know how the differences between English textbooks with good and poor quality. They should be able to recognize the strengths and weaknesses of English textbooks (Article 4).

In accordance with the examples presented above, two forms of personal references are identified. The first personal reference is the masculine reference that apparently portrayed by the appearance of he which is associated with Harmer. In addition, the plural personal reference is plainly portrayed by the appearance of they which are associated with the students within Article 3 and English teachers within Article 4.

In addition, some examples of the implementation of demonstrative reference in the introduction section are presented as follows.

(1) Since textbooks become the basic need for both teachers and students, there are many publishers produce textbooks. Those textbooks are then sold in some bookstores with various prices (Article 4).

(2) They lacked vocabulary and pronunciation and did not get enough time to practice vocabulary and pronunciation. This was caused by low students' motivation to learn English (Article 5).

(3) According to Kurikulum 2013, there are four major skills which have to be taught in English teaching and learning process. Those are receptive skills including listening and reading, and productive skills including speaking and writing (Article 7).

According to the three aforementioned examples, two forms of demonstrative references are pointed out. The first demonstrative reference is clearly exemplified through the implementation of those which is related to textbooks in Article 4 and four major skills in Article 7. Furthermore, the second demonstrative reference is the implementation of this which 
is related to lacked vocabulary and pronunciation and did not get enough time to practice vocabulary and pronunciation.

Additionally, the examples of comparative references in the introduction section are displayed as follows.

(1) Speaking is not tested in final examination. It makes the teacher gives less attention to speaking than other skills (Article 1).

(2) Furthermore, writing is the most complex macro skill since it involves the use of knowledge and skills (Article 3).

(3) These opportunities are needed by the students to encourage them to use English in communicating, and it also will give more chances to the students to practice their speaking skill (Article 7).

Based on the examples presented above, three forms of demonstrative references are pointed out. The first demonstrative reference is plainly defined by the use of other which is associated with skills within Article 1. In addition, the second demonstrative reference is clearly outlined in Article 3 by the appearance of the most complex which is related to writing as the macro skill. Furthermore, the third demonstrative reference is pointed out by the occurrence more which is associated with chances for the students to practice their speaking skill within Article 7.

It has been previously stated that reference provides a particular type of cohesion that is interconnected to a specific meaning of information which is referred to in a sentence or a text (M. A. K. Halliday, 1976). In other words, the use of reference in a sentence or a text is supposed to create a semantic meaning between two or more sentences. The role of reference to create a semantic meaning between two or more sentences is discovered in the introduction section of research articles written by the undergraduate students of English Language Teaching. For instance, within Article 4, the personal reference of they is linked with English teachers creating a semantic relation to explain that the English teachers should be able to recognize the strengths and weaknesses of English textbooks to know how to differentiate between English textbooks with good and poor quality. Meanwhile, within Article 7, the demonstrative reference of those is associated with four major skills building a semantic relation to explain that there are four major skills which are receptive skills including listening and reading as well as productive skills including speaking and writing in accordance with Kurikulum 2013. Furthermore, within Article 7 as well, the comparative reference of the most complex is related with writing to define that compared to other macro skills, writing is the most complex one since it requires the use of knowledge and skills.

The similar results are found in the prior research in which there are a total number of 494 appearances of reference displaying the fact that reference is the highest employed type of grammatical cohesion within the texts being examined (Andayani et al., 2014). Above all, another research carried out by Abimanyu (2016) also reveals that there are 290 personal pronouns, 25 demonstrative pronouns, and 29 comparative pronouns appear in order to create a semantic meaning between each sentence within the text being analyzed. In a nutshell, the 
utilization of three types of references is considered crucial in creating a semantic relation among sentences not only within the introduction section of research article but also within other types of genre text as well.

\subsubsection{Ellipsis}

The third classification of grammatical cohesion, which is the ellipsis, defines the structural relationship in a specific text in order to create a cohesion. In the present research, two forms of ellipsis, namely the nominal ellipsis and verbal ellipsis, are recognized to be employed to portray the cohesion of the introduction section of a research article. On the contrary, none of the introduction section of research articles written by the undergraduate students of English Language Teaching implements the clausal ellipsis.

As the first form of ellipsis, several instances of nominal ellipsis are presented as follows.

(1) ....some others are poor at the quality (Article 4).

(2) Making them memorize many new vocabularies and creating a good strategy in teaching would be a challenge for the teacher (Article 10).

According to the aforementioned examples, two forms of nominal ellipsis are pointed out. The first nominal ellipsis is clearly exemplified through the implementation of some others which is employed since textbooks provided in the bookstores within Article 4 is omitted. Furthermore, the second nominal ellipsis is the implementation of them which is used as the students of Legal English within Article 10 is omitted.

Additionally, the examples of verbal ellipsis in the introduction section are displayed as follows.

(1) The second problem (0) was the lack of accuracy (Article 2).

(2) The motivation (0) can be got from the teacher who is speaking English in the class, the media that the teacher uses, and the sources of the learning (Article 5).

(3) The features (0) cover clustering, redundancy, reduced forms, performance variables, colloquial language, rate of delivery, stress, rhythm, intonation of English and interaction (Article 8).

Based on the examples presented above, three forms of verbal ellipsis are highlighted. The first verbal ellipsis within Article 2 is plainly presented by omitting related to students' speaking skill and substituting it by zero. Furthermore, the full sentence of Article 5 should be the motivation to speak, to practice their vocabulary as the beginning, to create the ideas and to practice the pronunciation as the modal to speak. Also, the third example of verbal ellipsis within Article 8 is clearly defined by omitting that make speaking a difficult language skill and substituting it by zero.

Ellipsis is regarded as one category of grammatical cohesion to explain the structure as well as the correlation between sentences and the important aspect of a texture (M. A. K. Halliday, 1976). In relation to the suggested theory, it is uncovered that all of the ellipsis 
disclosed in the introduction section of research articles written by the undergraduate students of English Language Teaching solely focuses on creating a cohesion by referring to a structural relation established within the introduction section. For example, within Article 10, the nominal ellipsis of them is employed to deal with the nominal group within the text by omitting students of Legal English to create a cohesion. Meanwhile, within Article 2, the verbal ellipsis of the second problem is implemented to deal with the verbal group within the text by omitting related to students' speaking skill to build a cohesive force within the introduction section.

The deficiency of clausal ellipsis is also located in the prior research conducted by Abimanyu (2016), even though there are two examples for each nominal ellipsis and verbal ellipsis within the texts being analyzed. Furthermore, it is also noteworthy to show that ellipsis is the lowest employed type of grammatical cohesion as there is only 1 ellipsis found from 698 cohesive ties implemented within numerous narrative texts being examined (Andayani et al., 2014). The present findings are in accordance with a theory that asserts that substitution and ellipsis appear in numerous dialogues yet rarely appear in narrative or descriptive texts (M. A. K. Halliday, 1976).

\subsubsection{Conjunction}

The fourth classification of grammatical cohesion, which is the conjunction, creates a cohesion by correlating the linguistic elements within a particular text (M. A. K. Halliday, 1976). In the present research, all forms of conjunction, which are the additive conjunction, adversative conjunction, causal conjunction, as well as temporal conjunction, are employed to disclose the cohesion of the introduction section of a research article. As the first form of conjunction, several instances of additive conjunction are portrayed as follows.

(1) The second was that interesting media were rarely used to support the teaching and learning process. And the last was that the teacher did not give enough examples for the students when he asked them to perform (Article 1).

(2) Lastly, they need to revise their drafts and then refine their texts. Moreover, the students' writings will be assessed based on some aspects such as content, organization, vocabulary, grammar and mechanics (Article 3).

(3) It means that CSR improves students' reading comprehension skills, increases their vocabularies, enhances cooperative skills, and enriches content area learning. Moreover, it helps students organize information based on categories, makes them become more active readers and helps them remember new vocabulary and other information (Article 9).

According to the three aforementioned examples, two forms of additive conjunction are pointed out. The first additive conjunction is clearly exemplified through the appearance of and to associate the first and the second sentences within Article 1. Furthermore, the second additive conjunction is the implementation of moreover to reveal the correlation between the first and the second sentences within Article 3 and Article 9. 
Anis Firdatul Rochma \& Sulis Triyono

In addition, some examples of the implementation of adversative conjunction in the introduction section of research articles written by the undergraduate students are presented as follows.

(1) Besides, the teacher of English also expected that each student should master English in order to be able to support their future career. However, the facts were in contrast with the expectation (Article 2).

(2) For that reason, speaking is important for the students to master. Yet, some students have low ability in speaking (Article 7).

(3) The learning resources usually were in the forms of print and non-print materials. Unfortunately, printed Legal English books were rarely found in the market (Article 10).

Based on the examples presented above, three forms of adversative conjunction are highlighted. The first adversative conjunction is plainly defined by the use of however to reveal the contrary expectation within Article 2. Furthermore, the second adversative conjunction is clearly outlined by the appearance of yet to disclose the contrary expectation within Article 7. Also, the expression of unfortunately is also employed to portray the contrary expectation within Article 10.

Additionally, some examples of the implementation of causal conjunction to create a cohesion in the introduction section are shown as follows.

(1) In the process of writing, students should have adequate knowledge of the topic that will be executed. Thus, they should have proper writing skills. (Article 3).

(2) To do that, they need to know some aspects related to textbooks, such as content, language, and presentation. Therefore, English teachers should do evaluation on some English textbooks to determine whether they are good or not (Article 4).

(3) The materials used in the teaching and learning process should be contextualized with the needs of the students of every grade in the school. Hence, to make students able to achieve English materials, students are equipped with a set of term of textbook as their reference or guide for what they should learn (Article 6).

In accordance with the examples presented above, three forms of causal conjunction are identified. The first causal conjunction is portrayed by the appearance of thus in order to reveal the relation between the first and second sentences. In addition, the use of therefore and hence are also plainly employed to create a cohesive introduction section within Article 4 and Article 6.

Above all, an example of the implementation of temporal conjunction in the introduction section is displayed as follows. 
(1) Firstly, they need to decide the title of their texts. Secondly, they need to make outline of their texts. Thirdly, they should develop the outline into paragraphs. Lastly, they need to revise their drafts and then refine their texts (Article 3).

The occurrence of the temporal conjunction is portrayed by the appearance of firstly, secondly, thirdly, and lastly as a means of sequence in order to show a cohesion within Article 3.

All of the conjunction revealed in the introduction section of research articles written by the undergraduate students of English Language Teaching solely focuses on creating a cohesion through the implementation of conjunctive elements to relate one sentence with the continuing sentences within the text. For example, within Article 9, the additive conjunction of moreover is employed to add an additional information about CSR that is CSR improves students' reading comprehension skills, increases their vocabularies, enhances cooperative skills, enriches content area learning, as well as helps students organize information based on categories, makes them become more active readers, and helps them remember new vocabulary. Meanwhile, within Article 7, the adversative conjunction of however is employed to express the contrary expectation that even though the students are expected to master English but the facts were in contrast with the expectation. Furthermore, within Article 3, the causal conjunction of thus is implemented to define the association between the cause and the consequence that is in order to have adequate knowledge of the topic that will be executed so the students should have proper writing skills. Lastly, within Article 3, the temporal conjunctions of firstly, secondly, and thirdly are employed to define the related events in terms of the timing of occurrences.

Similarly, the four forms of conjunction are also found within the texts being analyzed by Abimanyu (2016) in which there are 199 appearances of additive conjunction, 52 appearances of adversative conjunction, 8 appearances of causal conjunction, and 33 appearances of temporal conjunction. In addition, Abimanyu (2016) also states that additive conjunction is employed frequently within the texts since it is considered to be more uncomplicated compared to the other types of conjunction. The present statement is in line with the research conducted by Andayani et al., (2014) as the research results reveal that the additive conjunction is being frequently employed within the texts being examined. However, the results of the present research uncover that causal conjunction is implemented more frequently compared to the other types of conjunction portraying the fact that the introduction section of a research article is likely to define a relationship between the cause and the consequences of a particular issue.

\subsection{Lexical Cohesion}

The second type of cohesion, which is the lexical cohesion, generally deals with the cohesive effect with the selection of non-grammatical elements. In the present research, it was discovered that reiteration was employed in one out of ten introduction sections. On the contrary, none of the introduction section of a research article implemented collocation to present the lexical cohesion. 
Anis Firdatul Rochma \& Sulis Triyono

\subsubsection{Reiteration}

As one of the two types of lexical cohesion, the reiteration is employed in one out of ten research articles, especially in the introduction section of a research article. An example of the implementation of reiteration in the introduction section is displayed as follows.

(1) The legal staff need to use legal English in their work, for example as lawyer or litigators, paralegals or legal studies, legal secretaries or trainee lawyer (Article 10).

The example of reiteration displayed in the introduction section of a research article written by the undergraduate students of English Language Teaching merely focuses on the occurrence of specific words under one superordinate word in order to create a cohesive force. For instance, within Article 10, the term of legal staff is the superordinate word or the general word of lawyer or litigators, paralegals or legal studies, and legal secretaries or trainee lawyer. In the aforementioned example, a superordinate word is employed to disclose that the legal staff consisting of lawyer or litigators, paralegals or legal studies, legal secretaries or trainee lawyer need to use legal English in their work. In other words, the terms of lawyer or litigators, paralegals or legal studies, legal secretaries or trainee lawyer are considered to be the specific words of legal staff in which those terms are employed to build a cohesive force in the introduction section of Article 10.

As the type of lexical cohesion to restate the lexical item in which it is either restated directly or through the implementation of synonym and a superordinate (M. A. K. Halliday, 1976), the appearance of reiteration in the introduction section of research article is considered very low indeed. On the contrary, in the prior research carried out by Abimanyu (2016), the appearance of reiteration are discovered in numerous forms, which are 570 appearances of repetitions, 14 appearances of synonyms, 14 appearances of superordinate, and 3 appearances of general words. Moreover, it is also discovered that there are 107 appearances of reiteration in the narrative texts being examined (Andayani et al., 2014). The lack of reiteration and collocation in the introduction section of research article implies that the writers are likely to rarely utilize the same words in emphasizing a certain issue in the research article.

\subsection{Introduction Section of Research Article with Cohesive Markers}

In accordance with the findings, it is revealed that the number of sentences occurs in the introduction section is not likely to be a factor of the cohesion appearances. In a research conducted by Kuncahya (2015) pertinent to the cohesion factors, it was stated that a text with more sentences tends to have a high cohesion compared to the ones with middle and low cohesion. This is due to the fact that the highly cohesive text tends to employ more cohesive devices in order to associate every sentence within the text. However, the present research discovers that a highly cohesive introduction section does not have significantly more sentences compared to the middle and low cohesive introduction sections. For instance, Article 7 analyzed in the present research is considered to be the highly cohesive introduction section compared to 
the others since it employs ten types of grammatical cohesion yet it only consists of 20 sentences. On the other hand, Article 8 is likely to be the middle cohesive introduction section as it employs six types of grammatical cohesion with 21 sentences included within the text. In addition, Article 6, which is considered to be the lowest cohesive introduction section, employs only four grammatical cohesion with fifteen sentences occurs within the text. As a consequence, it can be inferred that the number of sentences appears in the text is not likely to be a factor of cohesion since, in the present research, the number of sentences occurs in the high, middle, and low cohesive introduction section is not remarkably distinctive.

Furthermore, according to the findings and discussion in the present research, it is displayed that the appearance of reference outnumbers the appearance of other types of cohesion in which it is in line with the previous research carried out by Abimanyu (2016) and Andayani et al. (2014). Hence, it is noteworthy to assert that the semantic relation is mostly to be carried out through the utilization of grammatical markers rather than lexical markers. Even though a text with grammatical cohesion is believed to be the low cohesive text, as the grammatical cohesion is implicit and it also needs to possess an adequate prior knowledge to decode the inferences (McNamara, 2011), the grammatical cohesion employs within the introduction section of research article analyzed in the present research is not likely to cause a comprehension issue. That is to say, although the cohesive ties of grammatical cohesion are considered to be too implicit, it is important to state that the grammatical cohesion employed in most of the introduction section within the present research is considered to be able to assist the readers in filling the gaps in order to comprehend the topic as well as the importance of the research articles by clearly disclosing the interconnection among each sentence within the texts. What is more, even though none of the research articles employs substitution and collocation as an effort to create a cohesion within the introduction section, other types of cohesion implement within the texts are believed to be able to aid the readers in the process of building a meaningful, notable and eloquent inference pertinent to the topic of the research articles written by the undergraduate students of English Language Teaching.

\section{CONCLUSION}

The present research merely focuses on investigating the cohesion of the introduction section of research articles written by the undergraduate students of English Language Teaching. According to the findings and discussion, it is uncovered that the grammatical cohesion, especially the reference, is considered to be the highest type of cohesion employed in the introduction section as a strategy to disclose the correlation among each sentence within the research articles. However, the introduction sections of research articles written by the undergraduate students of English Language Teaching are still scarce of the lexical cohesion while, in fact, a text with lexical cohesion is considered to be a highly cohesive text as the relation established by the lexical cohesion is considered more explicit compared to the one established by the grammatical cohesion. Nevertheless, the grammatical cohesion implemented within the introduction sections of research articles analyzed in the present research are believed 
Anis Firdatul Rochma \& Sulis Triyono

to be able in assisting the readers to create a significant and remarkable inference related to the topic and noteworthiness of the research articles.

\section{REFERENCES}

Abimanyu, S. (2016). A Discourse Analysis of Cohesion in the Narrative Texts Used in The Textbooks Entitled "Pathway to English" for Senior High School Grades X and XI. Bachelor Thesis. Yogyakarta State University.

Andayani, P. O., Seken, K., \& Marjohan, A. (2014). an Analysis of the Cohesion and Coherence of the Students' Narrative Writings in Smp Negeri 2 Banjar. Journal of English Language Education Program Post Graduate Program of Ganesha University of Education Singaraja, Indonesia.

Briones, R. R. Y. (2016). Textual Analysis through Systemic Functional Linguistics. Journal of English Language Teaching and Linguistics, 1(2). https://doi.org/10.21462/jeltl.v1i2.27

Hirano, E. (2009). English for Research article introductions in English for specific purposes : A comparison between Brazilian Portuguese and English. English for Specific Purposes, 28(4), 240-250. https://doi.org/10.1016/j.esp.2009.02.001

Holtom, D. (1999). Enjoy Writing Your Science Thesis or Dissertation. London: Imperial College Press.

Johnson, M. (2017). Improving Cohesion in L2 Writing: A Three-Strand Approach to Building Lexical Cohesion. English Teaching Forum, 55(4), 2-13. Retrieved from http://search.ebscohost.com/login.aspx?direct=true \&db=eric \&AN=EJ1166137\&site=ehostlive

Jordan, R. R. (1999). Academic writing course; Study skills in English. Education. England: Pearson Education Limited.

Kendal, S. (2015). How to Write a Research Paper. In How to Write a Research Paper. UK: Bookbon. https://doi.org/10.14705/rpnet.2017.emmd2016.643

Loi, C. K., \& Evans, M. S. (2010). Cultural differences in the organization of research article introductions from the field of educational psychology: English and Chinese. Journal of Pragmatics, 42(10), 2814-2825. https://doi.org/10.1016/j.pragma.2010.03.010

M. A. K. Halliday. (1976). Cohesion in English. London: Longman.

Manan, N. A. A., \& Raslee, N. N. (2018). Explicit Discourse Marker Instruction to Improve Coherence and Cohesion in Academic Writing. International Journal of Academic Research in Business and Social Sciences, 8(1), 465-483. https://doi.org/10.6007/IJARBSS/v8-i1/3820

Rakhmawati, A. (2013). English Research Articles Written by Indonesian Academics : Coping with Common Practices and Rhetorical Diversity. 3rd International Conference on Foreign Language Learning and Teaching, (2002), 265-275.

Safnil. (2013). A Genre-Based Analysis on the Introductions of Research Article Written by Indonesian Academics. TEFLIN Journal, 24 (2), 180-200.

Sheldon, E. (2011). Journal of English for Academic Purposes Rhetorical differences in RA introductions written by English L1 and L2 and Castilian Spanish L1 writers. Journal of English for Academic Purposes, 10(4), 238-251. https://doi.org/10.1016/j.jeap.2011.08.004 
Swales, J. M., Feak, C. B., Johns, A. M., \& Arbor, A. (2004). Academic Writing for Graduate Students: Essential Tasks and Skills (Michigan Series in English for Academic \& Professional Purposes). Michigan Series, USA Course prerequisites English language skills at the level B2 according to CEFR. Michigan: The Michigan University Press.

Turabian, K. L. (2013). A Manual for Writers of Research Papers, Theses, and Dissertations. Chicago: University of Chicago Press. Retrieved from http://collections.chadwyck.co.uk.sire.ub.edu/initCritRefSearch.do?listType=abell\&initialis $\mathrm{e}=\mathrm{abell}$ 